\title{
Safety Guideline for a Generic Train Travelling on Different Platform Scenarios under the Influence of Crosswind
}

\author{
Izuan Amin Ishak ${ }^{1 *}$, Rahmah Mahmudin',NorAfzanizam Samiran' ${ }^{1}$, ZuliazuraMohd Salleh', \\ Nofrizalidris Darlis ${ }^{1}$ \\ ${ }^{1}$ Faculty of Engineering Technology, Universiti Tun Hussein Onn Malaysia, Edu Hub Pagoh, 84600, Johor, Ma- \\ laysia, izuan@uthm.edu.my
}

\begin{abstract}
The rapid development of train industry has allowed for the train to travel at much higher speeds. However, at high speed, issues regarding the resulting aerodynamic loads are a major concern especially when trains travelling under the influence of crosswind conditions. In this study, numerical techniques were adopted to assess the aerodynamic effects on the generic train as it is moving on different platform conditions (i.e. flat ground, embankment and bridge). The embankment case is varied based on the slope angle while the bridge case is differed based on the shape of girder wing. The influence of crosswind on the moving train is also conducted in which the incident flow angle $(\Psi)$ is varied from $0^{\circ}$ to $90^{\circ}$. Results shows that the aerodynamic loads are magnified as the train travels on higher altitude platforms. Analysis of the results can also be categorised into two flow regimes based on the incident flow angle $(\Psi)$. The maximum value for lift were found at small range of incident flow angle $\left(\Psi \leq 45^{\circ}\right)$ or also known as the slender body-flow regime. Otherwise, at larger incident flow angle $\left(\Psi \geq 60^{\circ}\right.$ ) or also known as the bluff body-flow regime, the side force and the rolling moment reached its critical values. Lastly, the results from the aerodynamic loads attained in this study is utilized for the assessment on the safety guidelines for train operation based on the 'critical wind speed for vehicle overturning'. The study concludes that the 'critical wind speed for vehicle overturning' ( $\left.U_{R, \text { critical }}\right)$ is the worst condition for a train moving on an embankment under the influence of crosswind which also led to the slowest 'train critical speed' $\left(U_{t, \text { critical }}\right)$. At a certain crosswind condition $(\Psi)$, for any kind of rail vehicles travelling on any kind of infrastructures, the result of $U_{R, \text { critical }}$ was found to be on the same linear line relationship with respect to $U_{t, \text { critical }}$.
\end{abstract}

Key words: Aerodynamic Loads, Crosswind, Flow Regime, Generic Train, Safety Guideline

\section{INTRODUCTION}

In the past few years, making the railway vehicles lighter has been the highlight to increase their speed, conserve energy, and reduce noise and vibration. Even though these approaches entail to improve the vehicle performances, they also leave the trains susceptible to overturning under a strong crosswind. Crosswind for an instant is a problematic factor for the stability of a ground vehicle. Today, most as buses, trucks, and cars, are also subjected to crosswind disturbances. In the scope of rail transport, alertness on safety factors especially the vehicle's crosswind stability has grown significantly in the community [1], [2].It has turn into an important gauge in the authorization process of railway [2]. Additionally, it has also become an alarming sign, especially in countries with the high-speed train (HST) networks [3]. Hence, it is hugely important to evaluate the safety of a railway vehicle operating under the influence of crosswinds.

Aerodynamic loads play a major role in determining the safety factors of train operation. With the additional infrastructure scenarios, the condition is expected to become much more critical as it will worsen the aerodynamic properties of the train. The combination of all these factors will lead to the accumulated risk of violating the mechanical safety conditions. Generally, it is clear that with the information of aerodynamic loads gathered from the experimental and numerical analyses, the condition for which the critical aerodynamic loads happen can be identified. However, the main question is how to utilize this information into something that can be easily correlated with the actual train operation so that the guideline for the train's safety criteria can be introduced.

In the past, the methodology of evaluating safety guidelines for rail vehicle operation was explored [4]-[10]. From most of these studies, the introduction of the 'critical wind speed for vehicle overturning' parameter has been widely used to assess the safety criteria for any train operation.By definition, the critical wind speed for vehicle overturning is the wind speed when there is zero load on the windward wheels [8]. It can be determined by the static balance analysis of external forces acting on the vehicle. In 1972, Kunieda[4] from the Japanese National Railways recommended a technique for the static analysis of a railway vehicle overturning due to a crosswind, which is called ' $\mathrm{Ku}$ nieda's Formula'. In the feedback review, the critical wind speed for vehicle overturning as calculated using Kunieda's formula showed good agreement with those estimated for actual overturning accidents at that time [11]. Since then, Kunieda's formula has been extensively adopted to assess the safety of newly designed vehicles (to avoid overturning accidents) in Japan. Meanwhile, in 2003, Hibino et al. [6] revised Kunieda's Formula after thoroughly analysing investigations of various overturning accidents due to crosswinds. The revised formula is called the 'Detailed Equa- 
tion', which incorporates the external forces and the displacement of the car body as suggested by Hibino et al.[7]. This new method has an advantage of more detailed assessment of aerodynamic force that particularly affects overturning [12].The criteria of both methods are summarized in Table 1.

In 2015, Kikuchi and Suzuki [11] has systematically investigated the influence of aerodynamic force coefficients on the critical wind speed for vehicle overturning for metergauged line vehicles. It is done by calculating the critical wind speed for vehicle overturning for a given amount of change in the aerodynamic force coefficients. Their key results can be summarized as follows (a) the influence of the side force coefficients is highly significant on the critical wind speed for vehicle overturning (b) the influence of the lift force coefficients and rolling moment coefficients on the critical wind speed for vehicle overturning is less than that of the side force coefficients. However, both of these coefficients should not be disregarded since the results of the critical wind speed for vehicle overturning are influenced by $6-11 \%$ when these coefficients are excluded from the equations.

Table 1: Differences between the Kunieda's formula and the Detailed Equation[12]

\begin{tabular}{|l|l|l|}
\hline \multicolumn{1}{|c|}{$\begin{array}{c}\text { Items } \\
\text { compared }\end{array}$} & \multicolumn{1}{c|}{$\begin{array}{c}\text { Kunieda's } \\
\text { Formula }\end{array}$} & \multicolumn{1}{|c|}{$\begin{array}{c}\text { Detailed } \\
\text { Equation }\end{array}$} \\
\hline $\begin{array}{l}\text { Characteristics } \\
\text { of the formula }\end{array}$ & $\begin{array}{l}\text { Simple analytical } \\
\text { formula that se- } \\
\text { cures margin of } \\
\text { safety by assuming } \\
\text { larger height of } \\
\text { centre of gravity }\end{array}$ & $\begin{array}{l}\text { Analytical equa- } \\
\text { tion using detailed } \\
\text { dynamic models }\end{array}$ \\
\hline Wind & Crosswind only & $\begin{array}{l}\text { Diagonal wind } \\
\text { resultant of natu- } \\
\text { ral wind and wind } \\
\text { acting on front of } \\
\text { running train }\end{array}$ \\
\hline $\begin{array}{l}\text { Aerodynamic } \\
\text { force acting on } \\
\text { vehicle }\end{array}$ & $\begin{array}{l}\text { Considering side } \\
\text { force only, assum- } \\
\text { ing the side force } \\
\text { coefficient is } 1.0\end{array}$ & $\begin{array}{l}\text { Considering the } \\
\text { side force, lift } \\
\text { force and moment }\end{array}$ \\
\hline $\begin{array}{l}\text { Effect of way- } \\
\text { side structures }\end{array}$ & $\begin{array}{l}\text { Not taken into } \\
\text { account (assuming } \\
\text { flat ground) }\end{array}$ & $\begin{array}{l}\text { Considering the } \\
\text { aerodynamic } \\
\text { force coefficient }\end{array}$ \\
\hline
\end{tabular}

Issues associated with crosswinds in the operation of modern high-speed trains can be major problems in certain countries. However, the assessment of crosswind safety in most countries is quite different from that of Japan [9], [13]-[17]. In Japan, static analyses are mainly used, but in Europe, dynamic analyses such as multi-body simulations are mostly used. For instance, based on the quasi-static analysis of Baker [9], in investigating the lateral stability of the train in crosswinds, several effects including the destabilizing influence of aerodynamic loads, track curvature, vehicle suspension, aerodynamic admittance, and track roughness have to be considered [9].Therefore, an equation was formulated, which leads to the introduction of 'generic accident wind speed curves' to representthe value of dimensionless overturning wind speed in terms of wind direction (yaw angle) and normalized vehicle speed. The information on this so-called accident wind speed curves are important as it gives a guideline in regard of train operation safety. This new introduction parameter is almost similar with the critical wind speed for vehicle overturning and could be a useful tool as it indicates the condition when the magnitude of the critical wind speed will occur.

Alternatively, referring to Rezvaniet al.[10], the prediction of train stability under the crosswind effect can be inferred in mechanical interpretation. Distribution of aerodynamic loads based on the lateral and lifting forces as well as the particular position of the vehicle's center of gravity is important to be considered for analysis. This allows for the conversion of all loads into the overturning momentum about the lee-rail. Thus, the identification of the most plausible condition in the vehicle overturning can be justified. Based on the techniques, a method to predict the wind speed that is capable of overturning a rail vehicle along a straight ideal track is proposed. This is measured based on the concept of momentum conservation about the lee-rail.

To sum up, there are various ways that can be considered for the evaluation of safety criteria of a rail vehicle operation. There are differences in the methodology of each idea, but the end result shows crucial information with regards to the guideline of train safety operation. In this study, the objective lies in the assessment of safety criteria utilizes the method revised by Hibino et al.[6] which called the ' $D e$ tailed Equation'. This methodology is chosen due to the fact that it is an improvement from the previous technique developed by Kunieda[4] and a simplification of static analyses over the more complicated method in dynamic analyses by most of European countries. Based on the study by Kikuchi and Suzuki[11],critical wind speed for vehicle overturning varies with respect to the different incident flow angle $(\Psi)$. Since the result for the critical wind speed is highly depended on the external forces that act on the vehicle, the value will be critical at high incident flow angle values in which most of the aerodynamic loads were at its optimum values.

This paper has been organized in the following way. Section 2 discusses the computational set-up inclusive the detailed model (train and its infrastructures), domain description, boundary condition and solution methodology. Section 3prevails the validated computational results based on the grid convergence study. This is done by a systematic method using the Grid Convergence Index (GCI) and the Richardson Extrapolation. Next, Section 4 providesthe aerodynamic loads value attained from the simulation. Results of aerodynamic forces and moment from the train travelling on various infrastructure conditions are compared directly with the baseline study (flat ground case). In Section 5,the theoretical background of the safety guideline assessment is explained and method for calculating the critical wind speed for vehicle overturning used in the examination is presented. Section 6entailed the safety guidelines for a train's operation based on the critical wind speed for vehicle overturning in respect to the crosswind yaw angle and the critical train speed. Finally, the conclusion is stated in the last section of the article. 


\section{COMPUTATIONAL SET-UP 2.1 Train model description}

The train model used in this study is a generic train model that acquired a blunt nose shape as shown in Figure 1. This specific model geometry is chosen so that validation and comparison study with previous investigators (experimentally by Sakuma et al.[18] and numerically by Osthet al.[19]) can be made.

The leading side and top edges on the front are rounded using an elliptical profile with major axis in the ellipse length of $0.07 \mathrm{H}$ and the minor axis length of $0.04 \mathrm{H}$ as can be seen in Figure 1(b). The side and top edges of the rear end of the vehicle are rounded with a circular radius $0.107 \mathrm{H}$ as can be seen in Figure 1(c). Both front and rear bottom edges are not rounded and thus sharp. The length of the train is $7 H$ while the width and height are both equal to $H$. $(W=H=0.56 \mathrm{~m})$.

Additionally, a train model with an ellipse nose shape was also analysed as shown in Figure 2. The front nose shape follows an elliptical profile with a major axis in the ellipse length of $2 \mathrm{H}$ and the minor axis length of $H$ as can be seen in Figure 2(a)-(b). All the other parameter follows the dimension as in the model withblunt nose shape.

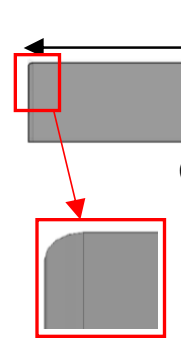

(b)

\section{$7 H$}

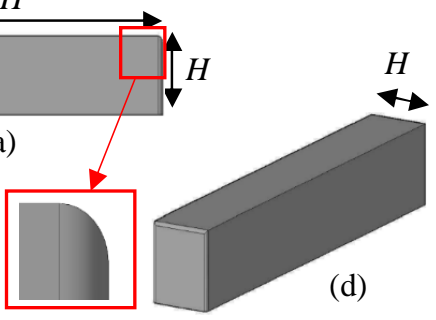

(c)
Figure 1: Geometry of the train model with blunt nose shape. (a) Side view (b) Close view of front corner with an elliptic rounding (c) Close view of rear corner with a circular rounding (d) Isometric view

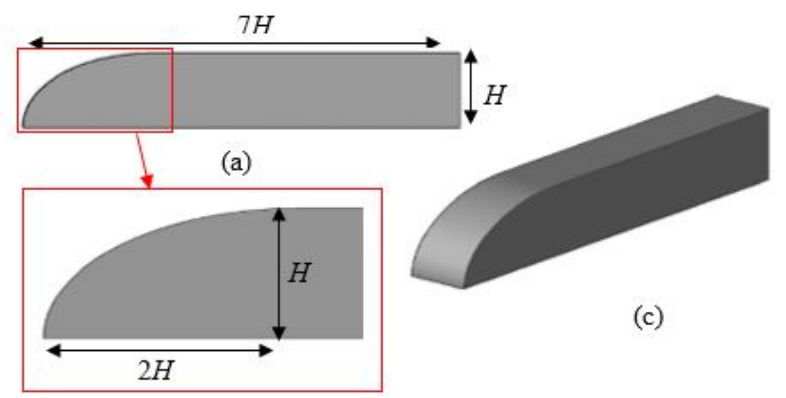

(b)

Figure 2:Geometry of the train model with ellipse nose shape(a) Side view (b) Close view of a front elliptic nose shape (c) Isometric view

\subsection{Infrastructure description}

The cases can be divided into three major categories of surfaces on which the generic train model is travelling: flat ground (FGC), embankment and bridge as shown in Figure 3-5.

Figure 4 shows the vehicle on top of an embankment. The crosswind $U_{\infty}$ affects the aerodynamic properties of the train differently when the slope of the embankment, $\theta$ is varied [1], [20], [21]. Three slope angles are investigated in this study, i.e. $\theta=150^{\circ}, \theta=160^{\circ}$ and $\theta=170^{\circ}$. The height of the embankment, $H$ is fixed at 6 meters which is based on the Technical Specifications for Interoperability (TSI) infrastructure scenario [1], and $B$ is 9.15 meters.

Figure 5 shows the vehicle on top of a bridge girder. There are three shapes of the bridge girder: (a) rectangular girder shape, (b) triangular girder shape, and (c) wedge girder shape. All models have the same $B / D$ ratio which is equal to $5: 1$ ( $D$ is the thickness of the girder shape). This parameter is expected to give different aerodynamic characteristics of the train [21], [22], [23].

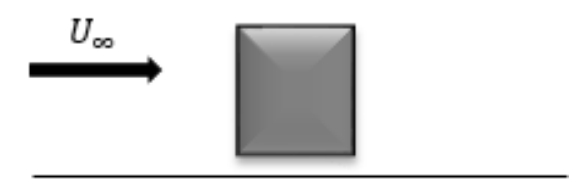

Figure 3: Problemgeometry and annotations for the crosswind over a generic train model travelling on a FGC (baseline case)

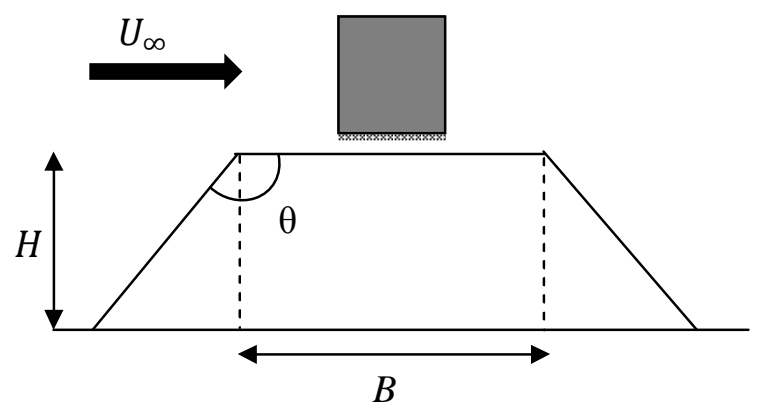

Figure 4:Problem geometry and annotations for the crosswind over a generic train model travelling on an embankment

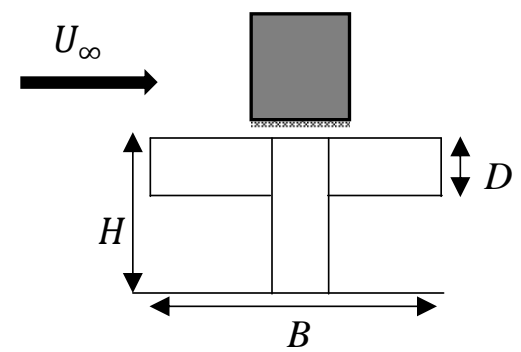

(a) 


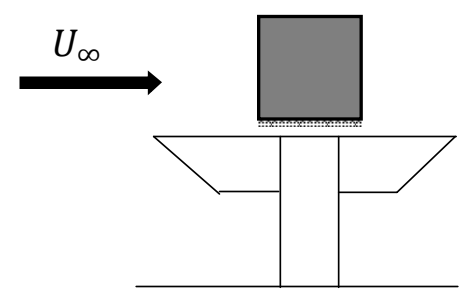

(b)

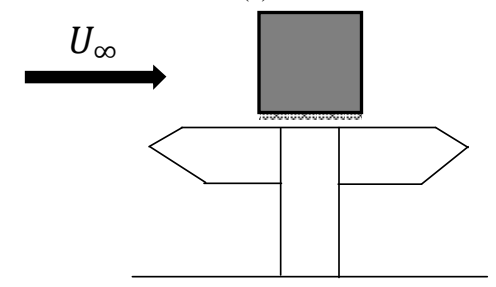

(c)

Figure 5: Problem geometry and annotations for the crosswind over a generic trainmodel travelling on a bridge

\subsection{Computational domain}

General guidelines on the distances between (i) the inlet and the vehicle and (ii) the vehicle and the outlet for the validation case are based on the previous investigations [24]-[27] i.e. distance from the inlet to the train model is $8 \mathrm{H}$ and distance from the train model to the outlet is $21 \mathrm{H}$.

The generic train model is placed $0.15 H$ above the ground in order to imitate the typical real train condition $[10,28]$. The placement of the train's model is also sufficiently far from the top and side walls (i.e. $10 H$ ) in order to minimize the near wall effects. Figure 6 visualized the domain for the case at $0^{\circ}$ yaw angle. A detailed summary of the domain size change for different crosswind situations is presented in Table 2.

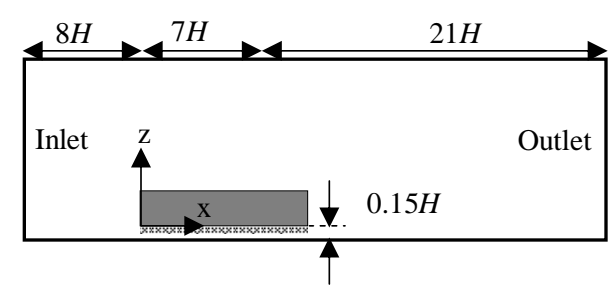

(a)

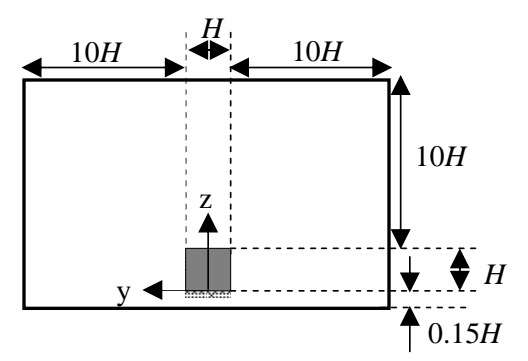

(b)

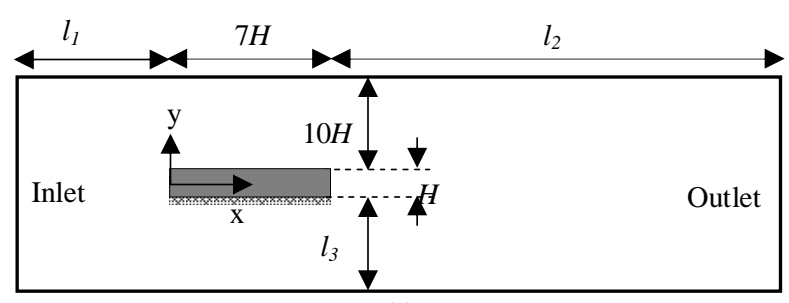

(c)

Figure 6: Computational domain used in the numerical investigation for $0^{\circ}$ yaw angle condition. (a) Side view (b) Front view (c)

Top view (Sketch only and not following the actual scale)

Table 2: Domain size parameter based on Figure 6(c) fordifferent cases of crosswind yaw angles

\begin{tabular}{|c|c|c|c|}
\hline YawAngle $(\Psi)$ & $l_{1}$ & $l_{2}$ & $l_{3}$ \\
\hline $0^{\circ}$ & $8 H$ & $21 H$ & $10 H$ \\
\hline $15^{\circ}$ & $8.4 H$ & $20.3 H$ & $10.5 H$ \\
\hline $30^{\circ}$ & $8.8 H$ & $18.2 \mathrm{H}$ & $12.8 H$ \\
\hline $45^{\circ}$ & $9.2 \mathrm{H}$ & $14.9 H$ & $16.1 H$ \\
\hline $60^{\circ}$ & $9.6 H$ & $10.5 H$ & $20.5 H$ \\
\hline $75^{\circ}$ & $10 H$ & $10 H$ & $21 H$ \\
\hline $90^{\circ}$ & $10 \mathrm{H}$ & $10 \mathrm{H}$ & $21 H$ \\
\hline
\end{tabular}

\subsection{Boundary condition}

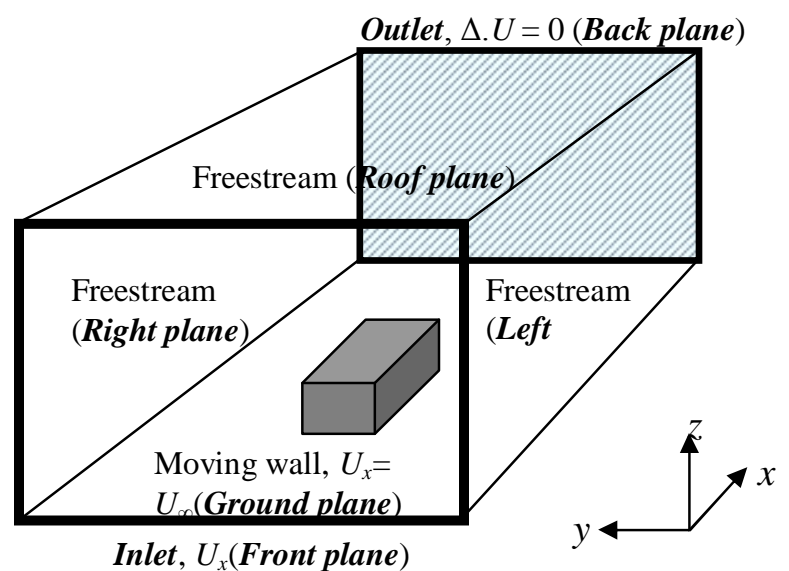

Figure 7: Boundary conditions used in the numerical investigation (not following the actual scale)

Visualizations of the boundary conditions are shown in Figure 7.The details of boundary conditions are explained as follows:

- Inlet (Front plane): Uniform velocity, which represents the free stream velocity $\left(U_{\infty}\right)$ is applied in the $x$-direction. For crosswind conditions $(\Psi>$ $0^{\circ}$ ), the resultant wind velocity will follow the component velocity vector based on the effective crosswind.

- Ground plane: The boundary type of moving wall is applied with the velocity component in the $x$ - 
direction equal to the inlet velocity $\left(U_{\infty}\right)$ in order to prevent the development of boundary layer on the ground plane. This is also to replicate the relative movement between the train and the ground.

- Outlet (Back plane): The homogenous Neumann boundary condition is applied at the outlet, meaning that the pressure gradient is equal to zero. This allows the flow pass through the outlet without affecting the upstream flow, provided that the upstream distance to the vehicle's body is large enough.

- Lateral side and roof plane: The patch type boundary condition with a freestream value similar to the inlet is used. (Note: the right plane will become an inlet whilst the left plane will transform to outlet boundary condition for crosswind cases e.g. wind with yaw angle $=15^{\circ}, 30^{\circ}, 45^{\circ}, 60^{\circ}, 75^{\circ}$, $90^{\circ}$ ).

- Train model surface: The no-slip condition is used.

\subsection{Solution methodology}

The flow around the train has been considered incompressible and is obtained by solving the incompressible form of the Reynolds Averaged Navier-Stokes (RANS) equations. The two equations which are Continuity and Navier-Stokes equations[30]for the incompressible flow are as follows:

$$
\begin{gathered}
\frac{\partial U_{i}}{\partial x_{i}}=0 \\
\frac{\partial U_{i}}{\partial t}+U_{j} \frac{\partial U_{i}}{\partial x_{j}}=-\frac{1}{\rho} \frac{\partial P_{i}}{\partial x_{i}}+\frac{\partial}{\partial x_{j}}\left(\mu \frac{\partial U_{i}}{\partial x_{j}}-\overline{\rho u_{\imath} u_{j}}\right)
\end{gathered}
$$

in which indices $i, j=1,2,3$ refer to the streamwise $-x$, cross-stream $-y$ and $-z$ direction in a Cartesian-coordinate system respectively. $U_{i}$ and $P_{i}$ are the time averaged terms, while $u_{i}$ is the fluctuation terms of velocity.

In this study, the OpenFOAM CFD software package is used to solve these governing equations. In this study, SST $k-\omega$ is used as it is more appropriate for external aerodynamics[31]. Detail numerical settings applied throughout all case study is presented as in Table 3 .

Table 3: Numerical methods used in OpenFOAM

\begin{tabular}{|c|c|c|c|}
\hline & cian & $\begin{array}{l}\text { differencing } \\
\text { scheme }\end{array}$ & unbounded \\
\hline \multicolumn{2}{|c|}{$\begin{array}{l}\text { Pressure-velocity } \\
\text { coupling }\end{array}$} & SIMPLE & $\begin{array}{l}\text { Used as } \\
\text { steady flow } \\
\text { algorithm }\end{array}$ \\
\hline $\begin{array}{l}\text { Turbu- } \\
\text { lence } \\
\text { models }\end{array}$ & RANS & $k-\omega$ & $\begin{array}{l}\text { Shear- } \\
\text { Stress- } \\
\text { Transport } \\
\text { (SST) }\end{array}$ \\
\hline \multirow{3}{*}{$\begin{array}{l}\text { Wall } \\
\text { func- } \\
\text { tions }\end{array}$} & $k$ & $\begin{array}{l}\text { kqRWall- } \\
\text { Function }\end{array}$ & $\begin{array}{c}\text { Acts as a } \\
\text { zero- } \\
\text { gradient } \\
\text { condition for } \\
\text { modelled } k\end{array}$ \\
\hline & $\omega$ & $\begin{array}{l}\text { omegaWall- } \\
\text { Function }\end{array}$ & $\begin{array}{l}\text { Automatic } \\
\text { wall func- } \\
\text { tions condi- } \\
\text { tion for } \omega\end{array}$ \\
\hline & $v_{t}$ & $\begin{array}{l}\text { nutkWall- } \\
\text { Function }\end{array}$ & $\begin{array}{c}\text { Generates } \\
\text { near-wall } \\
\text { profile for } v_{t} \\
\text { based on } \\
\text { modelled } k\end{array}$ \\
\hline
\end{tabular}

\begin{tabular}{|c|c|c|c|}
\hline \multicolumn{2}{|c|}{ Discretization } & Scheme & $\begin{array}{c}\text { Descrip- } \\
\text { tion }\end{array}$ \\
\hline \multirow{2}{*}{ Time } & steadyState & - \\
\hline \multirow{2}{*}{ Spatial } & $\begin{array}{c}\text { Gradi- } \\
\text { ent }\end{array}$ & $\begin{array}{c}\text { Central } \\
\text { differencing }\end{array}$ & $\begin{array}{c}2^{\text {nd }} \text { order } \\
\text { central dif- } \\
\text { ferencing }\end{array}$ \\
\cline { 2 - 5 } & $\begin{array}{c}\text { Diver- } \\
\text { gence }\end{array}$ & QUICKV & $3^{\text {rd }}$ order \\
\cline { 2 - 4 } & Lapla- & Gauss linear & $2^{\text {nd }}$ order \\
\hline
\end{tabular}

\section{VALIDATION STUDY}

\subsection{Grid convergence study}

Solutions to three different grid refinements which represent fine, medium, and coarse grids are simulated with the aim of investigating the effect of grid dependency. These different grid resolutions are carefully chosen based on grid refinement ratio (r) as shown in Table 4.

Table 4: Grid parameter for case A, B and C where subscripts 1, 2 and 3 represents case $\mathrm{A}, \mathrm{B}$ and $\mathrm{C}$ respectively

\begin{tabular}{|c|c|c|c|}
\hline CASE & $\begin{array}{c}\text { A } \\
\text { (Fine) }\end{array}$ & $\begin{array}{c}\text { B } \\
\text { (Medium) }\end{array}$ & $\begin{array}{c}\text { C } \\
\text { (Coarse) }\end{array}$ \\
\hline $\begin{array}{c}\text { Total No. of } \\
\text { Cells, } \boldsymbol{N}\end{array}$ & $2,114,715$ & 951,838 & 359,838 \\
\hline $\begin{array}{c}\text { Average cell } \\
\text { size, } \boldsymbol{h}_{\text {ave }} \text { (m) }\end{array}$ & 0.0895 & 0.1168 & 0.1615 \\
\hline $\begin{array}{c}\text { Average } \boldsymbol{y}^{+} \\
\text {Refinement ra- } \\
\text { tio, } \boldsymbol{r}\end{array}$ & 81.76 & 83.28 & 113.59 \\
\hline \multicolumn{2}{|c|}{$r_{21}=1.31$} & $r_{32}=1.38$ \\
\hline
\end{tabular}

Based on Celiket al.[32], it is necessary that the ratio be at least greater than 1.3. Since the meshes are not uniform, the grid refinement ratio is calculated based on average grid $\operatorname{size}\left(h_{\text {ave }}\right)$. The grid refinement ratio $(r)$ and the average cell size $\left(h_{\text {ave }}\right)$ can be calculated as follows;

$$
r_{21}=\frac{h_{2}}{h_{1}}
$$




$$
\begin{aligned}
r_{32} & =\frac{h_{3}}{h_{2}} \\
h_{\text {ave }} & =\left[\frac{1}{N} \sum_{i=1}^{N}\left(\Delta V_{i}\right)\right]^{\frac{1}{3}}
\end{aligned}
$$

where $\Delta V_{i}$ is the volume of the $i^{\text {th }}$ cell, and $N$ is the total number of cells used for the computations.

The grid convergence study is accessed using the Richardson Extrapolation $\left(f_{\mathrm{RE}}\right)$ and Grid Convergence Index $(\mathrm{GCI})$ which can be calculated based on Equation (6)-(7). By definition, the value estimated from the Richardson $\left(f_{R E}\right)$ is the value that would result if the cell grid size tended to zero $(\mathrm{h} \rightarrow 0)$. Alternatively, the GCI value indicates that the percentage of the computed value is away from the value of the asymptotic numerical value. It shows an error band on how far the solution is from the asymptotic value and how much the solution would change with a further refinement of the grid. This is accomplished by comparing GCI results of various parameters between different levels of mesh resolutions. Bothof these indicators are essential in accessing a grid convergence study [33]-[35].

$$
f_{R E} \approx f_{1}+\left\lfloor\frac{\left(f_{1}-f_{2}\right)}{\left(r^{p}-1\right)}\right\rfloor
$$

where $\mathrm{r}$ is the refinement ratio as shown in Equations (3) (4) and $p$ is the order of accuracy.

$$
G C I_{i+1, i}=F_{S} \frac{\left|\varepsilon_{i+1, i}\right|}{f_{i}\left(r^{p}-1\right)} \times 100 \%
$$

To evaluate the extrapolated values of these solutions, it is important to firstly examine the convergence criteria. There are basically three possible convergence conditions:
a. $(0<R<1)$ for monotonic convergence
b. $(R<0)$ for oscillatory convergence
c. $(R>1)$ for divergence

where the convergence ratio $(R)$ is defined as follows:

$$
R=\frac{\varepsilon_{21}}{\varepsilon_{32}}
$$

Table 5 shows the results of different parameters obtained from the simulations of different mesh resolutions and corresponding extrapolated values based on the Richardson extrapolation. Monotonic convergence criteria are achieved since $0<R<1$ (refer to Table 6). This can be seen clearly from Figure 8 whichindicates how the value of the chosen parameter progressively moved in a converging pattern towards the Richardson extrapolated value. This also explained that the error, due to grid convergence, gradually decreased and the fine grid resolution $\left(\mathrm{GCI}_{21}\right)$ had a value of less than $1 \%$ for almost all the compared parameters. To put it briefly, as the GCI reduction from the coarser grid $\left(\mathrm{GCI}_{32}\right)$ to the finer grid $\left(\mathrm{GCI}_{21}\right)$ is relatively high, it can be said that the grid independent solution is nearly achieved, which concludes that further refinement of the grid will not

\begin{tabular}{|c|c|c|c|c|}
\hline CASE & $\mathrm{A}\left(f_{1}\right)$ & $\mathbf{B}\left(f_{2}\right)$ & $\mathrm{C}\left(f_{3}\right)$ & $f_{R E}$ \\
\hline$C_{d}$ mean & $\begin{array}{l}0.72 \\
48\end{array}$ & 0.7222 & 0.7031 & 0.7254 \\
\hline $\begin{array}{c}\text { Stagnation } \\
\text { Pressure } \\
\left(\frac{P}{\rho u_{\infty}^{2}}\right)\end{array}$ & $\begin{array}{l}0.49 \\
18\end{array}$ & 0.4910 & 0.4884 & 0.4923 \\
\hline $\begin{array}{l}\text { Base Pres- } \\
\text { sure }\left(10^{-3}\right) \\
\left(\frac{P}{\rho u_{\infty}^{2}}\right)\end{array}$ & $\begin{array}{c}- \\
4.0654\end{array}$ & $\begin{array}{c}- \\
4.1272\end{array}$ & $\begin{array}{c}- \\
4.3692\end{array}$ & $\begin{array}{c}- \\
4.0308\end{array}$ \\
\hline $\begin{array}{c}\text { Wake } \\
\text { Length (m) }\end{array}$ & $\begin{array}{l}0.57 \\
64\end{array}$ & 0.5723 & 0.5482 & 0.5778 \\
\hline
\end{tabular}
greatly impact the results of flow simulation [33], [37].

Table 5: Comparison of different parameters from different mesh resolutions and the extrapolated values calculated using the Richardson extrapolation

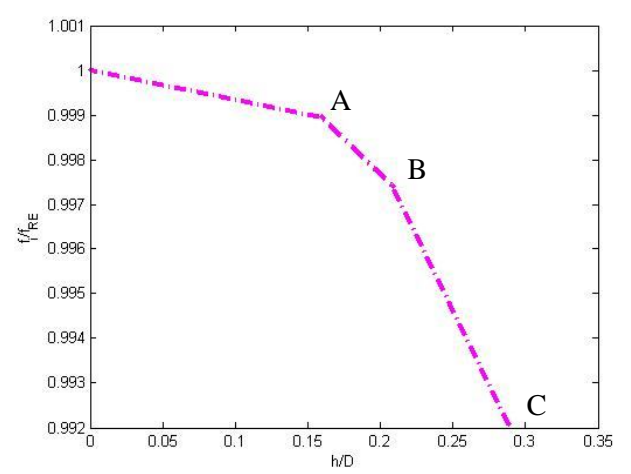

(a) Comparison of mean $C_{d}$ normalized by the extrapolated value, between three grid solutions and the Richardson extrapolation estimation. $f_{1} / f_{R E}=0.9992, f_{2} / f_{R E}=0.9956$ and $f_{3} / f_{R E}=0.9693$

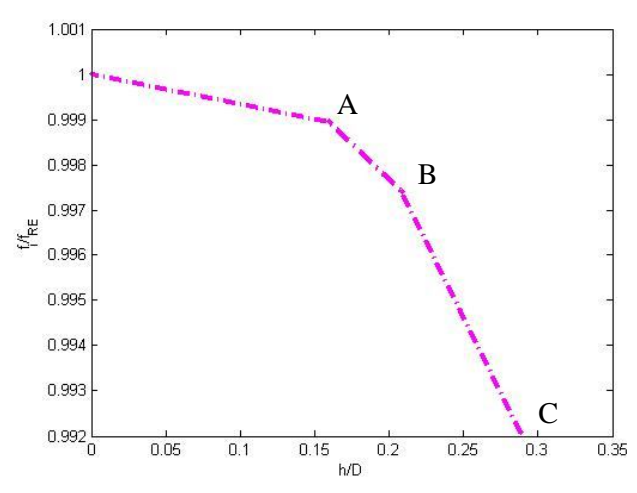

(b)Comparison of stagnation pressure normalized by the extrapolated value, between three grid solutions and the Richardson extrapolation estimation. $f_{1} / f_{R E}=0.9989, f_{2} / f_{R E}=0.9974$ and $f_{3} / f_{R E}=$ 0.9921 


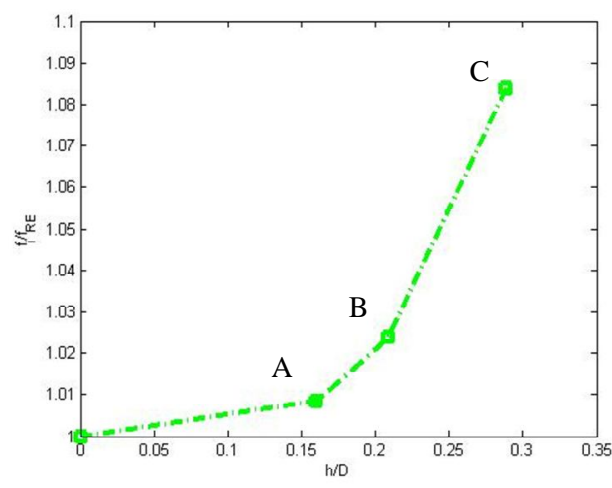

(c)Comparison of base pressure normalized by the extrapolated value between three grid solutions and the Richardson extrapolation estimation. $f_{1} / f_{R E}=1.0164, f_{2} / f_{R E}=1.0318$ and $f_{3} / f_{R E}=1.0923$

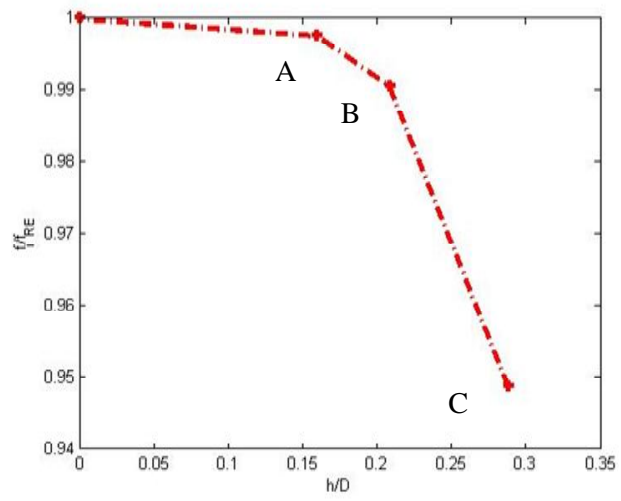

(d)Comparison of wake length normalized by the extrapolated value, between three grid solutions and the Richardson extrapolation estimation $f_{1} / f_{R E}=0.9976, f_{2} / f_{R E}=0.9905$ and $f_{3} / f_{R E}=0.9488$

Figure 8: Comparison of different integral parameters normalized by the extrapolated, between three grid solutions and Richardson extrapolation estimation

Table 6: Grid Convergence Index (GCI) for different parameters

\begin{tabular}{|l|c|c|c|c|c|}
\hline \multicolumn{1}{|c|}{ CASE } & $\begin{array}{c}\left|\boldsymbol{\varepsilon}_{\mathbf{3 2}}\right| \\
\left.\mathbf{( 1 0}^{-2}\right)\end{array}$ & $\begin{array}{c}\left|\boldsymbol{\varepsilon}_{\mathbf{2 1}}\right| \\
\left.\mathbf{( 1 0}^{-2}\right)\end{array}$ & $\boldsymbol{R}$ & $\begin{array}{c}\mathbf{G C I}_{\mathbf{3 2}} \\
\mathbf{( \% )}\end{array}$ & $\begin{array}{c}\mathbf{G C I}_{\mathbf{2 1}} \\
\mathbf{( \% )}\end{array}$ \\
\hline$C_{d}$ mean & 1.910 & 0.260 & 0.133 & 0.554 & 0.112 \\
\hline $\begin{array}{l}\text { Stagnation } \\
\text { Pressure }\end{array}$ & 0.260 & 0.080 & 0.293 & 0.326 & 0.131 \\
\hline $\begin{array}{l}\text { Base Pres- } \\
\text { sure }\left(10^{-3}\right)\end{array}$ & 0.024 & 0.006 & 0.255 & 2.906 & 1.049 \\
\hline $\begin{array}{l}\text { Wake } \\
\text { Length (m) }\end{array}$ & 2.407 & 0.410 & 0.170 & 1.195 & 0.297 \\
\hline
\end{tabular}

Furthermore, the detail assessment on the turbulence model and comparison study with the previous scholars can be refer to the reference Ishak et al.[35], [37]-[39].

\section{AERODYNAMIC LOADS OBTAINED IN THE SIMULATION}

In this study, the mean aerodynamic forces and the rolling moment are calculated. When integrated, these stresses give rise to the resultant load components, which are usually expressed in non-dimensional form by means of force and moment coefficients. These non-dimensional parameters are chosen so that comparison can be made regardless of the train's shapes, sizes or driving speed.

$$
\begin{gathered}
C_{s}=\frac{F_{S}}{\left(\frac{1}{2} \rho u^{2} A\right)}, C_{l}=\frac{F_{l}}{\left(\frac{1}{2} \rho u^{2} A\right)}, \\
C_{R L}=\frac{R_{R L}}{\left(\frac{1}{2} \rho u^{2} A H\right)}
\end{gathered}
$$

where $F_{s}$ is the side force, $F_{l}$ is the lift force, $R_{R L}$ is the rolling moment, $\rho$ is the density of air, $u$ is the wind velocity relative to the vehicle, $A$ is the projected surface area in the $x$-direction, and $H$ is the height of the train body.

Figure 9 illustrates the comparison of aerodynamic loads for a train travelling on different platform conditions with respect to various crosswind condition. As can be seen, the results are hugely depended on the crosswind conditions. This has bring about in the characterization of two flow regimes conditions as has been discussed by the past scholars [37], [40]-[43]. Tables 7-9lists down the value for aerodynamic load coefficients for all cases involved in the present study.

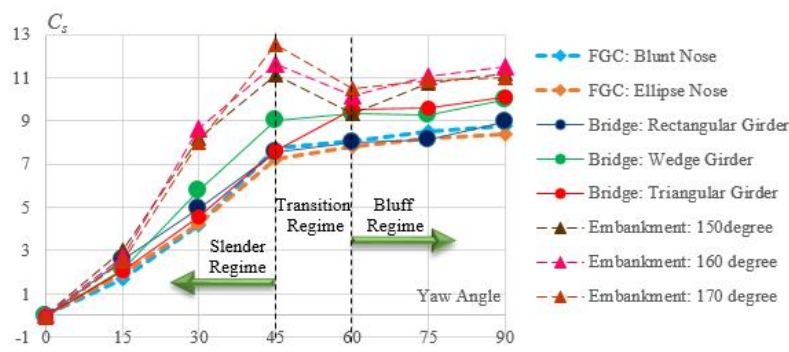

(a)

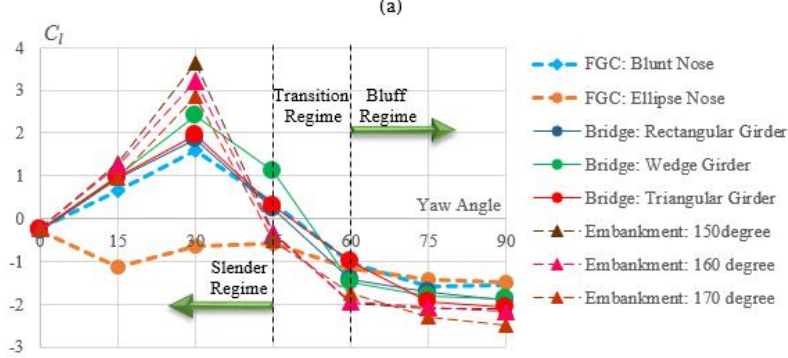

(b)

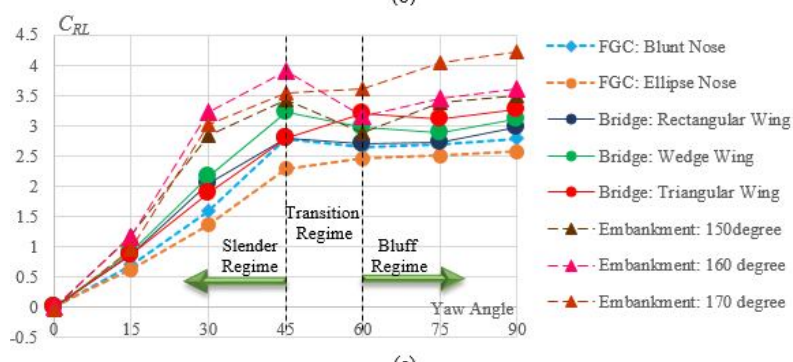

Figure 9: Comparison of the (a) side force $\left(C_{s}\right)$, (b) lift force $\left(C_{l}\right)$ and (c) rolling moment $\left(C_{R L}\right)$ with respect to different crosswind conditions for the train moving on various platforms 
Quantitatively, from the results obtained, two of the parameters i.e. the side force coefficient $\left(C_{s}\right)$ and the rolling moment coefficient $\left(C_{R L}\right)$ showed much larger values for the embankment cases compared to the bridge cases and the FGC. In the slender body flow regime $\left(\Psi \leq 45^{\circ}\right)$, the embankment with a $170^{\circ}$ slope recorded the highest $C_{s}$ value, whilst in the bluff body flow regime $\left(\Psi \geq 60^{\circ}\right)$, the embankment with a $160^{\circ}$ slope recorded the highest $C_{s}$ value. Meanwhile, for the bridge cases, in the slender body flow regime $\left(\Psi \leq 45^{\circ}\right)$, the bridge with the wedge girder shape had the worst $C_{s}$ condition, whilst in the bluff body flow regime $\left(\Psi \geq 60^{\circ}\right)$, the triangular girder case had the worst $C_{s}$ value. The same case happened for the rolling moment coefficient $\left(C_{R L}\right)$ whereby all cases showed a maximum value at $\Psi=45^{\circ}$ except for the embankment with a $170^{\circ}$ slope for which the value increased to a maximum value at $\Psi=90^{\circ}$. Among the infrastructure cases, the embankments provide the highest aerodynamic loads for both $C_{s}$ and $C_{R L}$ values. Contrariwise, $C_{l}$ is considered much more critical at a low range of yaw angles and its maximum value was recorded at $\Psi=30^{\circ}$. The values were slightly higher for the embankment cases, followed by the bridge cases and the FGC.

The result from aerodynamic loads attained are reflected based on the flow regimes. As mentioned earlier, there are two types of flow regimes occur when a train travels pass through a crosswind condition. In slender body flow regime $\left(\Psi \leq 45^{\circ}\right)$, the change in the $C_{s}$ and $C_{R L}$ was almost linear with the yaw angle. For the $C_{l}$, the graph showed a fluctuating increase to a maximum value before decreasing. On the other hand, in the bluff body flow regime $\left(\Psi \geq 60^{\circ}\right)$, the aerodynamic loads (i.e. $C_{s}, C_{l}$, and $C_{R L}$ ) are less affected by the change in the crosswind yaw angles.

\section{METHOD FOR CALCULATING CRITICAL WIND SPEED FOR VEHICLE OVERTURNING}

\subsection{Definition}

The 'critical wind speed for vehicle overturning' can be defined as the wind speed at which the vehicle that is subjected to a crosswind begins to overturn. When the vehicle is exposed to wind-induced external forces, the windward wheel load is reduced. This is because the moment around the leeward wheel/rail contact point acts on the vehicle, and the lateral and roll displacements of the car body are generated due to the deformation of the vehicle suspension systems [6]. When the windward wheel load becomes zero, the wind speed is defined as the critical wind speed for vehicle overturning.

\subsection{Outline of the Detailed Equation}

The static balance of the moment around the wheel/rail contact point is used to obtain the critical wind speed for vehicle overturning. The vehicle model used for measuring the critical wind speed by the Detailed Equation is shown in Figure 10. The symbols in Figure 10 used throughout this study are defined as follows:
$F_{s} \quad:$ Side force due to crosswind $[\mathrm{N}]$

$F_{l} \quad:$ Lift force due to crosswind [N]

$m_{B} \quad$ : Half mass of car body $[\mathrm{kg}]$

$m_{T} \quad$ : Mass of bogie $[\mathrm{kg}]$

$\alpha_{y} \quad$ : Lateral vibrational acceleration of the car body $\left[\mathrm{m} / \mathrm{s}^{2}\right]$

$\alpha_{u} \quad$ : Unbalanced centrifugal acceleration $\left[\mathrm{m} / \mathrm{s}^{2}\right]$

$g$ : Gravitational acceleration $\left[\mathrm{m} / \mathrm{s}^{2}\right]$

$C_{A} \quad$ : Centre of wind force

$G_{B} \quad$ : Centre of gravity of the car body

$G_{T} \quad$ : Centre of gravity of the bogie

$e \quad$ : Distance between the centre of gravity of the car body and the centre of the wind force [m]

$h_{B C} \quad:$ Height of the wind force from the rail top [m]

$h_{G B}$ : Height of the centre of gravity of the car body from the rail top [m]

$h_{G T} \quad$ : Height of the centre of gravity of the bogie from the rail top [m]

$h_{B 1} \quad$ : Height of the centre of the car body from the rail top $[\mathrm{m}]$

$h_{B 2} \quad$ : Height of the car body [m]

$P_{R} \quad$ : Right side wheel load [N]

$P_{L} \quad$ : Left side wheel load [N]

$y_{B} \quad$ : Lateral displacement of the car body [m]

$\varphi_{B} \quad$ : Roll displacement of the car body [rad]

$2 b$ : Distance between wheel/rail contact points [m]

Figure 10 shows the condition of a vehicle travelling on a canted curve and is blown by a crosswind from the inside of the curve. Basically, there are three forces that have considerable influence on vehicle overturning: wind force due to crosswind, unbalanced centrifugal force on a curve, and lateral vibrational inertia force. These three forces are considered in the Detailed Equation. In Figure 10, the lateral and roll displacements of the vehicle subjected to externalforces are $y_{B}$ and $\varphi_{B}$, respectively. These displacements can be obtained by considering the static balance of potential energy stored in suspension systems, such as axle spring and air spring [7].

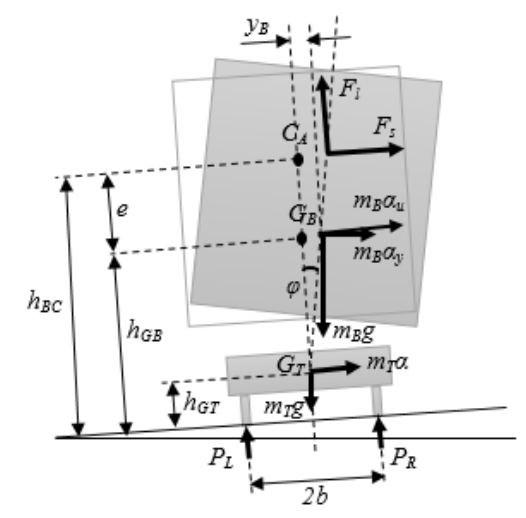

Figure 10: Model for calculating the critical wind speed [6]

Among the three forces mentioned earlier, the wind force due to crosswind has the utmost influence on overturning a vehicle. In the Detailed Equation, the side force $F_{s}$ in the $y$ - 
direction, the lift force $F_{l}$ in the z-direction (see Equation (9)), and the height of the wind force $\mathrm{h}_{\mathrm{BC}}$ (see Equation (10)) are considered, as shown in Figure 10.

$$
h_{B C}=h_{B 1}+\frac{C_{R L}}{C_{s}} h_{B 2}
$$

The rolling moment coefficient $C_{R L}$ is a non-dimensional quotient of rolling moment divided by $0.5 \mathrm{x} \rho u^{2} A$ (see Equation (9)). In Figure 10, the balance of the moment around the leeward wheel/rail contact point can be expressed as follows:

$$
\begin{aligned}
P_{L} \cdot 2 b=m_{T} g b+ & m_{B} g\left(b-y_{B}\right)-F_{l}\left(b-y_{B}+e \varphi_{B}\right) \\
& -h_{G T} m_{T} \alpha_{u}-h_{G B}\left(m_{B} \alpha_{u}+m_{B} \alpha_{y}\right) \\
& -h_{B C} F_{S}
\end{aligned}
$$

The wheel unloading ratio, $D^{*}$, which is one of the indices to evaluate the degree of danger against overturning, is defined by Equation (12). It is the quotient of $\Delta P$ i.e the decrease of the wheel load from the static wheel load divided by $\mathrm{P}_{0}$, i.e. the static wheel load. When $\mathrm{D}^{*}=1.0$, the windward wheel load becomes zero.

$$
D^{*} \equiv \frac{\Delta P}{P_{0}}
$$

where

$$
\begin{aligned}
& \Delta P=P_{0}-P_{L} \\
& P_{0}=\frac{\left(m_{B}+m_{T}\right) g}{2}
\end{aligned}
$$

Substitutuing Equation (11) into Equation (12), we can obtain the wheel unloading ratio $\mathrm{D}^{*}$ as follows:

$$
\left.\begin{array}{rl}
D^{*}=\frac{1}{(1+\mu) b}\left\{y_{B}\right. & +\overbrace{\left(h_{G B}+h_{G T}\right) \frac{\alpha_{u}}{g}}^{\begin{array}{c}
\text { Lateral vibrational } \\
\text { inertia force }
\end{array}}+\overbrace{h_{G B} \frac{\alpha_{y}}{g}}^{\begin{array}{c}
\text { Unbalance } \\
\text { fontrifugal }
\end{array}} \\
& +\overbrace{\frac{F_{S}}{m_{B} g} h_{B C}+\frac{F_{l}}{m_{B} g}\left(b-y_{B}+e \varphi_{B}\right)}^{\text {Wind forces due to crosswind }}
\end{array}\right\}
$$

where

$$
\begin{gathered}
\mu=\frac{m_{T}}{m_{B}} \\
e=h_{B C}-h_{G B} \\
y_{B}=C_{y} F_{B}+D_{y} M_{B} \\
\varphi_{B}=C_{\varphi} F_{B}+D_{\varphi} M_{B}
\end{gathered}
$$

and

$$
\begin{aligned}
& F_{B}=F_{S}+F_{u} \\
& M_{B}=-e F_{s}
\end{aligned}
$$

Here, $F_{b}$ is he total side force whereby $F_{s}$ is the side force due to crosswind and $F_{u}$ is the unbalanced centrifugal force (in this calculation, we set $F_{u}=0$ )[11]. $M_{B}$ is the total rolling moment. $\mathrm{C}_{\mathrm{y}}, \mathrm{C}_{\varphi}, \mathrm{D}_{\mathrm{y}}$, and $\mathrm{D}_{\varphi}$ are the coefficients that express the effects of a suspension system [6]. The specification of the vehicle can be referred to the appendix which is also based on the reference from previous study [5], [11]. The numerical values of the aerodynamic load coefficients used for the calculation are the same as those in Table 7-9.

Equation (15) is the Detailed Equation for rail vehicle overturning assessment. Supposing that the windward wheel load is zero $\left(D^{*}=1.0\right)$, and by solving the equation for $u$ that is included in $F_{s}$ and $F_{l}$, we can obtain the critical wind speed for vehicle overturning as defined above.

\section{RESULTS AND DISCUSSIONS ON THE SAFETY GUIDELINE FOR TRAIN OPERATION}

\subsection{Relation between critical wind speed for vehicle overturning and crosswind yaw angle}

In Figure 11, the result of the critical wind speed for vehicle overturning ( $\left.U_{R, \text { critical }}\right)$ with respect to various yaw angles of different platform scenarios is presented. As elaborated in detail earlier, the result is highly dependent on the aerodynamic force coefficients, thus, the profile of the critical wind speed curves is expected to vary with different platform scenarios.

It is also evident that the train vehicle operating on a FGC receives the highest tolerance of $U_{R, \text { critical }}$ especially with the elliptical nose model. This means that in order for the rail vehicle to get overturned, the wind speed should be particularly high especially at a small range of yaw angles (i.e. $U_{R, \text { critica }} \approx 37 \mathrm{~m} / \mathrm{s}$ for $\Psi \leq 30^{\circ}$ ). The second worst condition for the train to get overturned by the action of a crosswind is when it is travelling on a bridge (i.e. $U_{R, \text { critical }} \approx 30$ $\mathrm{m} / \mathrm{s}$ for $\Psi \leq 30^{\circ}$ ). Lastly, the worst plausible scenario with the lowest $U_{R, \text { critical }}$ allowed is the train running on top of an embankment (i.e. $U_{R, \text { critical }} \approx 23 \mathrm{~m} / \mathrm{s}$ for $\Psi \leq 30^{\circ}$ ). Since the world average mean wind speed is only around $3.28 \mathrm{~m} / \mathrm{s}$ [44], the possibility of a rail vehicle facing problems due to crosswinds is extremely low. However, it is also important to consider the possibility of strong wind gust, but since it is not in the scope of this study, such consideration is for future research. Pertaining to the potential gust-related issues, the fastest wind speed (not related to tornadoes) ever recorded was during the passage of Tropical Cyclone Olivia in Barrow Island, Australia, on 10 April 1996 which registered a maximum wind gust of $408 \mathrm{~km} / \mathrm{h}(113 \mathrm{~m} / \mathrm{s})$ [45]. 
Additionally, by looking at the graph pattern in Figure 11, a generalized scenario can also be concluded reflected on the different flow regimes. It is apparent that in the slender body flow regime, the highest magnitude of $U_{R, \text { critical }}$ is recorded for most of the cases. Furthermore, in this regime, the $U_{R, \text { critical }}$ also shows the largest magnitude differences between each case. It is also interesting to notice that at $\Psi=$ $45^{\circ}$, the lowest $U_{R \text {, critical }}$ is recorded for almost all cases. This signifies the flow behaviour transformation from the slender body flow regime to the bluff body flow regime at this crosswind condition. Moreover, the magnitude of the side force $\left(C_{s}\right)$ and the rolling moment $\left(C_{R L}\right)$ reach their optimal values (i.e. at $\Psi=45^{\circ}$ ). Both of these parameters are considered as the important aerodynamic loads in regard to train stability under the crosswind influence (see Figure 9). However, in the transition and bluff body flow regimes, the magnitude of $U_{R, \text { critical }}$ starts to converge towards the lower end value of $U_{R, \text { critical }}$ Even though the difference is quite small, the values of $U_{R, \text { critical }}$ of the different case scenarios can still be distinguished.

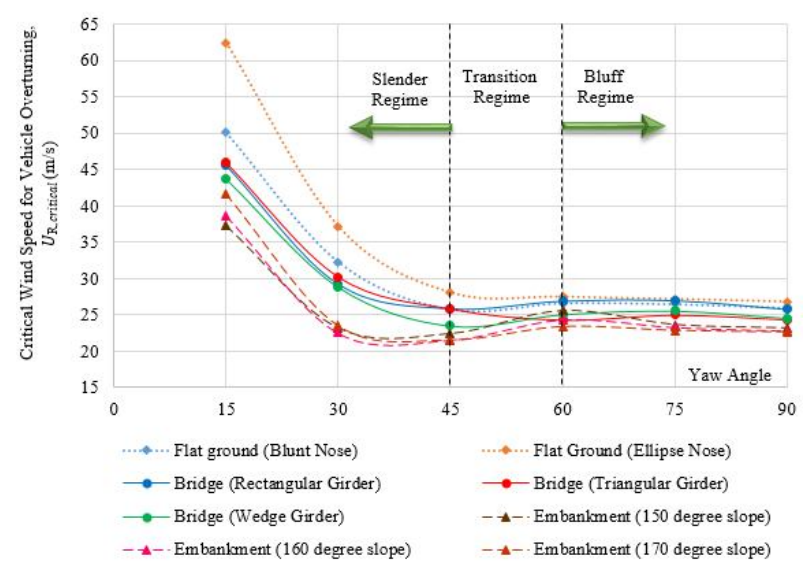

Figure 11:Relationship between the critical wind speed for vehicle overturning $\left(U_{R, \text { critical }}\right)$ and the resultant wind yaw angle for the train travelling on different platforms

\subsection{Relation between critical train speed and crosswind yaw angle}

Using the information from critical wind speed for vehicle overturning with respect to a certain crosswind yaw angle condition, the critical train speed $\left(U_{t, \text { critical }}\right)$ can be obtained based on the static balance of vector analysis. Figure 12shows the correlation between the $U_{t, \text { critical }}$ with respect to different crosswind yaw angles. At a lower yaw angle, the train can get a much higher speed especially for the train that travelling on the FGC. Based on the bar chart, at $\Psi=$ $15^{\circ}$, the train can travel up to a maximum speed of 500 $\mathrm{km} / \mathrm{h}$ on the worst platforms condition (i.e. the embankments), more than $550 \mathrm{~km} / \mathrm{h}$ when the train is travelling on the bridges, and up to $650 \mathrm{~km} / \mathrm{h}$ when the train is travelling on the FGC. Even greater speeds are acquired when the train model with the aerodynamic shape nose is considered (i.e. $U_{t, \text { critical }}>800 \mathrm{~km} / \mathrm{h}$ ). With the current technology, the highest train speed that has ever been recorded is $603 \mathrm{~km} / \mathrm{h}$ which is achieved by SC Maglev in Japan [46]. With the modern advancement of technology and expertise, together with high demand especially in developing countries, it has become more important to achieve a much higher operating speed for the rail vehicle. Figure 13lists the recently acquired top speed of high-speed trains in the world. Nevertheless, there is always a limit to each train design. In fact, this is in parallel with the objectives of the study which is to provide guidelines for train operation with respect to the possibility of accidents due to aerodynamic problems i.e. the influence of crosswinds.

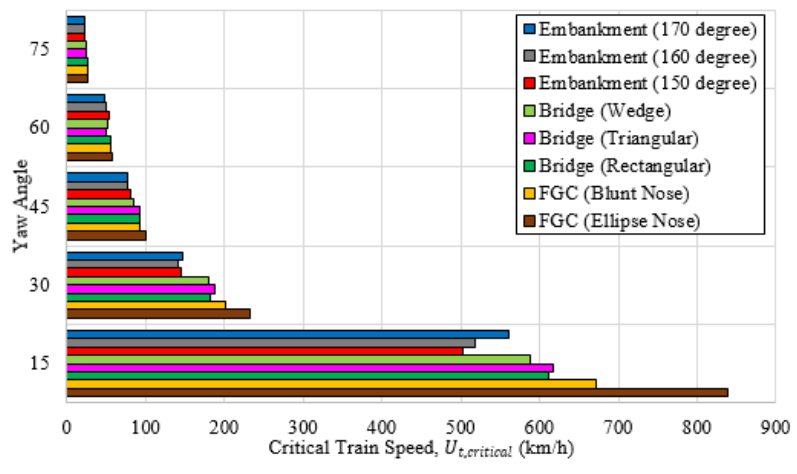

Figure 12:Relationship between the critical train speed ( $\left.U_{t, \text { critical }}\right)$ and the resultant wind yaw angles for the train travelling on different platforms

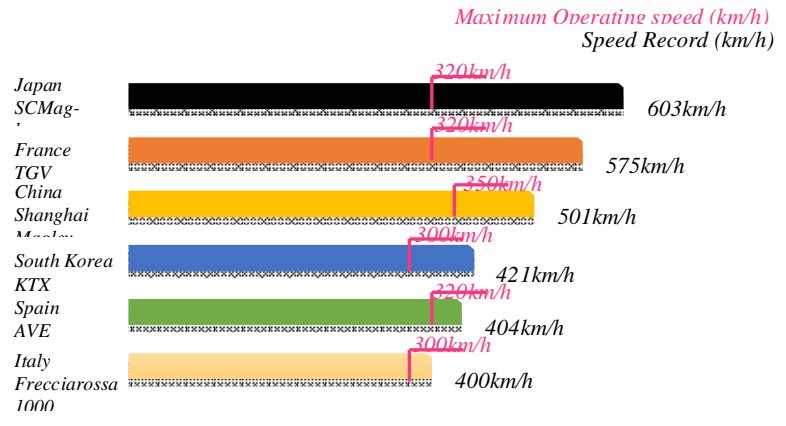

Figure 13: Comparison of train's top speed records with their maximum operating speed [46]

Nevertheless, based on Figure 12, as the yaw angle increases, the critical train speed $\left(U_{t, \text { critical }}\right)$ shows a considerable decrease in value. For example, $U_{t, \text { critical }}$ of the blunt nose train travelling on the FGC at $\Psi=15^{\circ}$ is $675 \mathrm{~km} / \mathrm{h}$, but at $\Psi=30^{\circ}$, the speed reduces to $200 \mathrm{~km} / \mathrm{h}$ which is about $70 \%$ decrease and $U_{t, \text { critical }}$ decreases even more at larger yaw angle conditions. However, as discussed earlier, it is also important to note that the direction of the crosswind relies on both the wind speed and the train speed. Due to a much lower wind speed in general, together with the considerably higher train's operating speed even for a regional train, the crosswind yaw angle typically lies at $\Psi \leq$ $40^{\circ}$ [47]. Therefore, it is much important to consider the important guidelines on the range of crosswind yaw angles (i.e. $\Psi \leq 40^{\circ}$ ) as it is more likely to happen in real life. However, it is also possible for the higher yaw angle to occur especially during an extremely low speed train operation or at the train's stagnant position. 
When comparison is made with the results of infrastructure platforms under which the train is travelling, the embankment cases allow the lowest $U_{t, \text { critical }}$ compared to the bridge cases. The outcome is coherent with the $U_{R, \text { critical }}$ as shown in Figure 11which indicates much lower values for the infrastructure cases obtained as compared to the FGC. On top of that, the results in this section also agree with the discussions on all the important aerodynamic loads as shown in Figures 9.Due to the higher critical aerodynamic loads for the $C_{s}$ and $C_{R L}$ at a higher range of yaw angles, the lower values of $U_{R, \text { critical }}$ and $U_{t, \text { critical }}$ are attained.

It is also interesting to notice that at a larger yaw angle ( $\Psi \geq$ $\left.60^{\circ}\right), U_{t, \text { critical }}$ is not hugely influenced by the different nose shapes of the train as shown in Figure 12. As the flow direction changes from parallel to perpendicular to the vehicle surface, the effect of the train's body is more significant on the aerodynamics of the train which in this case is not varied. Thus, at $\Psi \geq 60^{\circ}$, the $U_{t, \text { critical }}$ is almost comparable for all cases regardless of the different platforms under which the train is travelling.

\subsection{Relation between critical wind speed for vehicle overturning and critical train speed}

Interestingly, there is a unique relationship that can be established when comparison is made between $U_{R, \text { critical }}$ and $U_{t, \text { critical }}$. From Figures 14-15, a linear relationship is discovered for each of the crosswind yaw angle conditions even though the nose shapes of train model are altered, and the ground condition are varied. This means that for a specific wind direction, the value obtained for both $U_{R, \text { critical }}$ and $U_{t, \text { critical }}$ for different cases of trains creates a linear relationship that can be assembled into the same group. When compared with data from Kikuchi \& Suzuki [48], the line relationship is agree well. In conclusion, these guidelines could be used as an important benchmark for further studies regarding different configurations of trains and ground platforms. From the results attained, it can be concluded that both the critical wind speed of vehicle overturning $\left(U_{R, \text { critical }}\right)$ and the critical train speed $\left(U_{t, \text { critical }}\right)$ are largely dependent on the yaw angles (i.e. varying crosswind conditions).

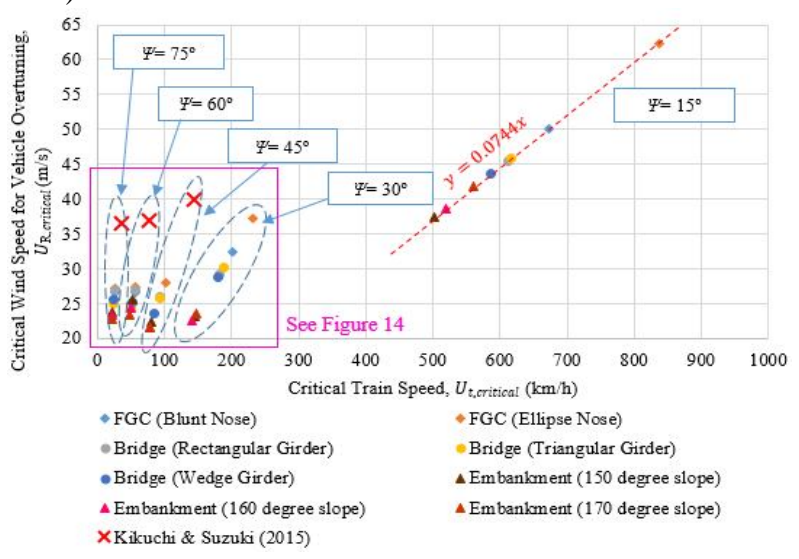

Figure 14: Relationshipbetween the critical wind speed for vehicle overturning $\left(U_{R, \text { critical }}\right)$ and the critical train speed $\left(U_{t, c r i t i c a l}\right)$ for the train travelling on different platforms

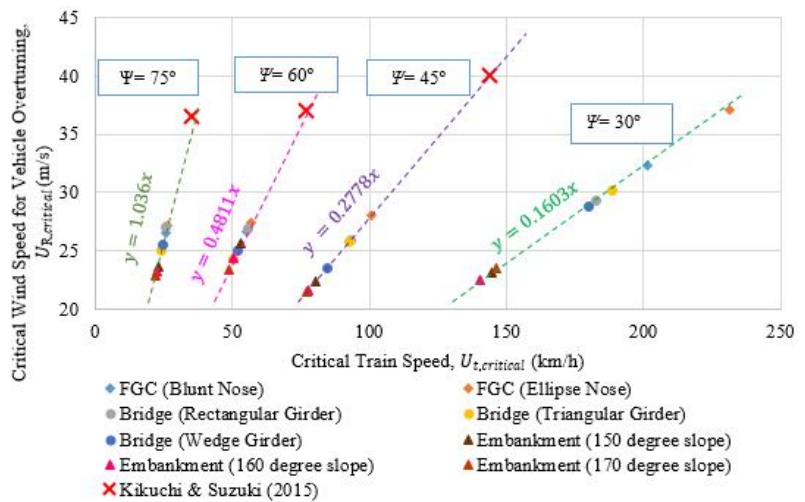

Figure 15:Relationship between the critical wind speed for vehicle overturning $\left(U_{R, \text { critical }}\right)$ and the critical train speed $\left(U_{t, \text { critical }}\right)$ for the train travelling on different platforms (close-up view)

\section{CONCLUSIONS}

In this study, investigations on the aerodynamic loads of a generic train model travelling under the crosswind influence were conducted for different platform conditions. As the research is fully based on the numerical approach, a detailed validation study was conducted. A mesh refinement study was explicitly performed to make sure the number of cells used in the simulation achieved the grid independence criteria. Fine grid mesh is in the excellent range with the extrapolated value retrieved from the Richardson theory. All variables for the fine grid mesh have shown a GCI value of less than $1 \%$ except for the base pressure. Hence, series of numerical simulation are carried out using the fine grid resolution. Results shows that the aerodynamic loads are magnified as the train travels on higher altitude platforms. The occurrence of two flow regimes signify the graph patterns based on slender body flow regime $\left(\Psi \leq 45^{\circ}\right)$ and bluff body flow regime ( $\Psi \geq$ $60^{\circ}$ ). The sensitivity of crosswind on aerodynamic loads are much affected in the slender body flow regime whilst the value is more or less constant in the bluff body flow regime.

The second half of this article presented the safety guidelines for a moving train under the crosswind influence. By using the already established methodology by past scholar, the method was fully utilized, and the results obtained were then further extended. The outcome showcased that the trains travelling on infrastructures had the lowest tolerance for the critical wind speed for vehicle overturning $\left(U_{R, \text { critical }}\right)$ compared to the FGC. The embankment configurations showed the worst values among the infrastructure cases. Due to this, the critical train speed $\left(U_{t, \text { critical }}\right)$ of the FGC was the highest value followed by the bridge cases and the embankment cases (the lowest value). Additionally, an interesting discovery on the relationship between the $U_{R, \text { critical }}$ and the $U_{t, \text { critical }}$ was found. At a specific crosswind condition, a linear relationship between the $U_{t, \text { critical }}$ and the $U_{R, \text { critical }}$ was established and can be applicable for the train moving on different platforms. In the end, this finding could be a very valuable tool as it can provide a benchmark for the investigation of different vehicle shapes, geometries and ground configurations in the near future. 


\section{APPENDIX}

Table A. Specifications of the vehicle

\begin{tabular}{|c|c|c|}
\hline & Notation & Value \\
\hline$F_{s}$ & $\begin{array}{l}\text { Side force due to crosswind } \\
{[\mathrm{N}]}\end{array}$ & $\begin{array}{l}\text { refer Figure } 9 \\
\text { (a) }\end{array}$ \\
\hline$F_{l}$ & $\begin{array}{l}\text { : Lift force due to crosswind } \\
\text { [N] }\end{array}$ & $\begin{array}{l}\text { refer Figure } 9 \\
\text { (b) }\end{array}$ \\
\hline$M_{B}$ & $\begin{array}{l}\text { Rolling moment due to } \\
\text { crosswind }[\mathrm{Nm})\end{array}$ & $\begin{array}{l}\text { refer Figure } 9 \\
\text { (c) }\end{array}$ \\
\hline$\alpha_{y}$ & $\begin{array}{l}\text { Lateral vibrational accelera- } \\
\text { tion of the car body }\left[\mathrm{m} / \mathrm{s}^{2}\right]\end{array}$ & 0.2 \\
\hline$\alpha_{u}$ & $\begin{array}{l}\text { : Unbalanced centrifugal accel- } \\
\text { eration }\left[\mathrm{m} / \mathrm{s}^{2}\right]\end{array}$ & 0.5 \\
\hline$h_{G B}$ & $\begin{array}{l}\text { : Height of the centre of gravity } \\
\text { of the car body from the rail } \\
\text { top }[\mathrm{m}]\end{array}$ & 0.45 \\
\hline$h_{B 1}$ & $\begin{array}{l}\text { : Height of the centre of the car } \\
\text { body from the rail top [m] }\end{array}$ & 0.364 \\
\hline$h_{B 2}$ & : Height of the car body [m] & 0.644 \\
\hline $2 b$ & $\begin{array}{l}\text { : Distance between wheel/rail } \\
\text { contact points }[\mathrm{m}]\end{array}$ & 0.56 \\
\hline $\begin{array}{l}C_{y} \\
D_{y} \\
C_{\varnothing} \\
D_{\varnothing}\end{array}$ & $\begin{array}{l}\text { : Coefficient representing the } \\
\text { influence of spring system of a } \\
\text { vehicle }\end{array}$ & $\begin{array}{c}6.42 \times 10^{-6} \\
-1.66 \times 10^{-6} \\
-1.66 \times 10^{-6} \\
1.84 \times 10^{-6}\end{array}$ \\
\hline
\end{tabular}

\section{ACKNOWLEDGEMENT}

This research was financially supported by Universiti Tun Hussein Onn Malaysia under UTHM Contract Grant (H523). The author would also like to acknowledge the Automotive and Combustion Synergies Technology Group (ACST) for giving the opportunity to carry out the project at the specified laboratory.

\section{REFERENCES}

[1] B. Diedrichs, M. Sima, A. Orellano, and H. Tengstrand, "Crosswind Stability of a High-Speed Train on a High Embankment," Proc. IMechE, Part F J. Rail Rapid Transit, vol. 221, no. 2, pp. 205225, 2007.

[2] M. E. X. Zhang, "Crosswind stability of vehicles under nonstationary wind excitation," Karlsruhe Institute of Technology, Karlsruhe, BadenWürttemberg, Germany, 2015.

[3] C. J. Baker, J. Jones, F. Lopez-calleja, and J. Munday, "Measurements of the Cross Wind Forces on Trains," J. Wind Eng. Ind. Aerodyn., vol. 92, pp. 547-563, 2004.

[4] M. Kunieda, "Theoretical study on the mechanics of overturn of railway rolling stock," Railw. Tech. Res. Rep., no. 793, 1972.

[5] Y. Hibino, T. Shimomura, and K. Tanifuji, "Verification of static analysis on railway vehicle overturning under crosswind," Trans. Japan Soc. Mech. Eng. Ser. C, pp. 1-8, 2009.

[6] Y. Hibino, T. Shimomura, and K. Tanifuji, "FullScale Experiment on the Behavior of a Railway
Vehicle being Subjected to Lateral," J. Mech. Syst. Transp. Logist., vol. 3, no. 1, pp. 35-43, 2010.

[7] Y. Hibino and H. Ishida, "Static analysis on railway vehicle overturning under crosswind," RTRI Rep., vol. 17, no. 4, pp. 39-44, 2003.

[8] T. Imai et al., "New train regulation method based on wind direction and velocity of natural wind against strong winds," J. Wind Eng. Ind. Aerodyn., vol. 90, no. 12-15, pp. 1601-1610, 2002.

[9] C. Baker, "A framework for the consideration of the effects of crosswinds on trains," J. Wind Eng. Ind. Aerodyn., vol. 123, pp. 130-142, 2013.

[10] M. Ali Rezvani and M. Mohebbi, "Numerical calculations of aerodynamic performance for ATM train at crosswind conditions," Wind Struct. An Int. J., vol. 18, no. 5, pp. 529-548, 2014.

[11] K. Kikuchi and M. Suzuki, "Study of aerodynamic coefficients used to estimate critical wind speed for vehicle overturning," J. Wind Eng. Ind. Aerodyn., vol. 147, pp. 1-17, 2015.

[12] Y. Kurihara, A. Oyama, K. Doi, and Y. Yasuda, "Introduction of new methods for train operation control in strong winds," JR EAST Tech. Rev., no. 27, pp. 17-22, 2011.

[13] G. Matschke and B. Schulte-Werning, "Measures and strategies to minimise the effect of strong cross winds on high speed trains," Proc. World Congr. Railw. Res., vol. E, pp. 569-575, 1997.

[14] P. E. Gautier, "Strong wind risks in railways, the DEUFRAKO crosswind program," Proc. World Congr. Railw. Res. (WCRR 2003), pp. 463-474, 2003.

[15] C. J. Baker, "Ground vehicles in high cross winds part I: Steady aerodynamic forces," J. Fluids Struct., vol. 5, no. 1, pp. 69-90, 1991.

[16] C. J. Baker, "Ground vehicles in high cross winds part II: Unsteady aerodynamic forces," J. Fluids Struct., vol. 5, no. 1, pp. 91-111, 1991.

[17] C. J. Baker, "Ground vehicles in high cross winds part III: The interaction of aerodynamic forces and the vehicle system," J. Fluids Struct., vol. 5, no. 2, pp. 221-241, 1991.

[18] Y. Sakuma and A. Ido, "Wind Tunnel Experiments on Reducing Separated Flow Region Tunnel Around Front Ends of Vehicles on Meter -Gauge Railway Lines Vehicles Pressure hole Tuft position," Quaterly Rep. RTRI, vol. 50, no. 1, pp. 20-25, 2009.

https://doi.org/10.2219/rtriqr.50.20

[19] J. Osth and S. Krajnovic, "Simulations of Flow around a Simplified Train Model with a Drag Reducing Device usign Partially Averaged NavierStokes," in Conference on Modelling Fluid Flow, 2012, vol. 12, pp. 1-8.

[20] F. Ekeroth, N. Kalmteg, J. Pilqvist, and J. Runsten, "Crosswind flow around a high-speed train on embankment," Chalmers University of Technology, Gothenburg, Sweden, 2009.

[21] M. Suzuki, K. Tanemoto, and T. Maeda, "Aerodynamic characteristics of train/vehicles under cross winds," J. Wind Eng. Ind. Aerodyn., vol. 91, no. 1-2, pp. 209-218, 2003.

[22] Q. Wang, H. Liao, M. Li, and C. Ma, "Influence of 
aerodynamic configuration of a streamline box girder on bridge flutter and vortex-induced vibration," J. Mod. Transp., vol. 19, no. 4, pp. 261267, 2011.

[23] L. Bruno and G. Mancini, "Importance of deck details in bridge aerodynamics," Struct. Eng. Int. J. Int. Assoc. Bridg. Struct. Eng., vol. 12, no. 4, pp. 289-294, 2002.

[24] H. Hemida and S. Krajnovic, "LES study of the influence of a train-nose shape on the flow structures under cross-wind conditions," J. Fluids Eng. Asme, vol. 130, no. 9, pp. 1-12, 2008.

https://doi.org/10.1115/1.2953228

[25] S. Krajnović and L. Davidson, "Large Eddy Simulation of the Flow Around an Ahmed Body," ASME 2004 Heat Transf. Eng. Summer Conf. Am. Soc. Mech. Eng., pp. 653-662, 2004.

[26] H. Hemida, S. Krajnovic, and L. Davidson, "LargeEddy Simulation of the Flow Around a Simplified High Speed Train Under the Influence of a CrossWind," 17th AIAA Comput. Fluid Dyn. Conf., no. June, pp. 1-17, 2005.

[27] CEN 14067-4, "Railway applications aerodynamics Part 4: Requirements and test procedures for aerodynamics on open track," Natl. Stand. Auth. Irel., 2013.

[28] A. M. Biadgo, A. Simonovic, J. Svorcan, and S. Stupar, "Aerodynamic characteristics of high speed train under turbulent cross Winds: A numerical investigation using unsteady-RANS method," FME Trans., vol. 42, no. 1, pp. 10-18, 2014.

[29] H. Hemida and S. Krajnović, "LES study of the influence of the nose shape and yaw angles on flow structures around trains," J. Wind Eng. Ind. Aerodyn., vol. 98, no. 1, pp. 34-46, 2010.

[30] B. Manshoor, I. Zaman, A. Khalid, M. F. Ghazali, and M. K. Khandelwal, "Effect of Streamwise Spacing on the Sound Generated by Flow through Two," Int. J. Adv. Trends Comput. Sci. Eng., vol. 9, no. 1, pp. 534-541, 2020.

[31] F. G. Ng and A. Chua, "Simulating the Effect of Non-Axial Airflow on the Motion of an Undriven Propeller," Int. J. Adv. Trends Comput. Sci. Eng., vol. 9, no. 1, pp. 153-159, 2020. https://doi.org/10.30534/ijatcse/2020/23912020

[32] I. B. Celik, U. Ghia, P. J. Roache, C. J. Freitas, H. Coleman, and P. E. Raad, "Procedure for Estimation and Reporting of Uncertainty Due to Discretization in CFD Applications," J. Fluids Eng., vol. 130, no. 7, p. 78001, 2008.

[33] M. Sukri, M. Ali, C. J. Doolan, and V. Wheatley, "Grid Convergence Study for a Two-Dimensional Simulation of Flow Around a Square Cylinder At a Low Reynolds Number," Seventh Int. Conderence CFD Miner. Process Ind. CSIRO, no. December, pp. 1-6, 2009.

[34] N. M. Maruai, M. S. M. Ali, M. H. Ismail, and S. A. Zaki, "Flow-induced vibration of a square cylinder and downstream flat plate associated with microscale energy harvester," J. Wind Eng. Ind. Aerodyn., vol. 175, pp. 264-282, 2018.

[35] I. A. Ishak, M. S. Mat Ali, and S. A. Z. ShaikhSalim, "Mesh size refining for a simulation of flow around a generic train model," Int. J. Wind Struct., vol. 24, no. 3, 2017.

[36] Q. A. Mulligan, M. Barimani, and S. I. Green, "Full-scale freight train underbody aerodynamics with application to track spraying," Int. J. Rail Transp., vol. 4, no. 3, pp. 151-166, 2016.

[37] I. A. Ishak, M. S. Mat Ali, M. F. Mohd Yakub, and S. A. Z. Shaikh Salim, "Effect of crosswinds on aerodynamic characteristics around a generic train model," Int. J. Rail Transp., vol. 7, no. 1, pp. 1-32, 2018.

[38] I. A. Ishak, M. S. M. Ali, and S. A. Z. S. Salim, "Numerical simulation of flow around a simplified high-speed train model using OpenFOAM," IOP Conf. Ser. Mater. Sci. Eng., vol. 152, pp. 3-14, 2016.

[39] I. A. Ishak et al., "Aerodynamic Characteristics Around a Generic Train Moving on Different Embankments under the Influence of Crosswind," $J$. Adv. Res. Fluid Mech. Therm. Sci., vol. 61, no. 1, pp. 106-128, 2019.

[40] M. Bocciolone, F. Cheli, R. Corradi, S. Muggiasca, and G. Tomasini, "Crosswind action on rail vehicles: Wind tunnel experimental analyses," $J$. Wind Eng. Ind. Aerodyn., vol. 96, no. 5, pp. 584610, 2008.

[41] M. Matsumoto, H. Ishizaki, C. Matsuoka, Y. Daito, Y. Ichikawa, and A. Shimahara, "Aerodynamic effects of the angle of attack on a rectangular prism," J. Wind Eng. Ind. Aerodyn., vol. 77-78, pp. 531542, 1998.

[42] E. W. M. Roosenboom, "Experimental analysis of the flow around a cylinder with a square crosssection," Thesis Submiss. Master Sci. Aerosp. Eng. Delft Univ. Technol., pp. 1-183, 2005.

[43] W. Khier, M. Breuer, and F. Durst, "Flow structure around trains under side wind conditions: A numerical study," Comput. Fluids, vol. 29, no. 2, pp. 179-195, 2000.

[44] C. L. Archer, "Evaluation of global wind power," J. Geophys. Res., vol. 110, no. D12, p. D12110, 2005. https://doi.org/10.1029/2004JD005462

[45] "New world record wind gust | World Meteorological Organization," 2010. [Online]. Available:

https://public.wmo.int/en/media/news/new-worldrecord-wind-gust. [Accessed: 14-Dec-2017].

[46] "Global High-Speed Train Ranking | GoEuro." [Online]. Available: https://www.goeuro.com/trains/high-speed.

[Accessed: 14-Dec-2017].

[47] J. L. Peters, "Aerodynamics of very high speed trains and maglev vehicles: State of the art and future potential," Int. J. Veh. Des. Spec. Publ. SP3 Impact Aerodyn. Veh. Des., pp. 308-341, 1983.

[48] K. Kikuchi and M. Suzuki, "Study of aerodynamic coefficients used to estimate critical wind speed for vehicle overturning," J. Wind Eng. Ind. Aerodyn., vol. 147, pp. 1-17, 2015. 